\title{
Convergence Between Theory and Experiment in Surface Chemistry and Catalysis-Gabor A. Somorjai Award and Symposium for Creative Research in Catalysis in Honor of Professor Jens Norskov
}

\author{
John T. Yates Jr.
}

Published online: 4 February 2010

(C) Springer Science+Business Media, LLC 2010

The articles in this issue of Topics in Catalysis are representative of the 31 presented papers at the 237th American Chemical Society Meeting, held in Salt Lake City, Utah March 22-26, 2009. The Symposium was organized to explore the current connections between theory and experiment in the field. The Symposium and the Somorjai Award are focused on the broad, deep and lasting contributions of Jens Norskov to the field of surface chemistry and catalysis.

The fields of surface chemistry and the closely-connected field of heterogeneous catalysis have experienced a renaissance in the last 20 years. New instruments to probe molecular behavior on model catalyst and surface-chemical systems have been melded together in the Symposium's structure with significant advances in theory which now deliver accurate analytic and predictive ability to surface chemistry. We are at a point where it is possible to select from either experiment or theory to obtain deep insight at the molecular and electronic level into the thermodynamic, kinetic and electronic behavior of surface species and surface reactions.

Most of the papers published in this issue of Topics in Catalysis are strongly flavored with theory. The casual reader can see that catalysis/surface chemistry has reached a level of understanding which was unheard of 20 years ago. Older topics, such as the Fischer-Tropsch reaction, the use of alloys for making modified metal substrates for enhanced catalytic activity, the role and behavior of surface defects in chemisorption and catalysis, the involvement of substrate adatoms in the formation of surface "organometallic-like" species, the catalytic oxidation of $\mathrm{CO}$, the key role of hydrogen on and under the surface, and the adsorption of water on a semiconductor- $\mathrm{TiO}_{2}$, are featured in the Symposium and in this issue of Topics in Catalysis, showing that the experimental and theoretical understanding of these classic problems has advanced significantly over two decades as illustrated by these papers.

I would like to thank Professor Gabor Somorjai for the invitation to be the guest editor of this issue of Topics in Catalysis. I would also like to thank Professor Jens Norskov for his active involvement in suggesting speakers for the Symposium. We all thank the American Chemical Society and the Division of Physical Chemistry for hosting a very successful Symposium.
J. T. Yates Jr. $(\bowtie)$

Department of Chemistry, University of Virginia,

Charlottesville VA 22904, USA

e-mail: johnt@virginia.edu 